\title{
As formas elementares de Durkheim no atual contexto político brasileiro
}

Ana Luiza da Silva Dias ${ }^{1}$

\section{RESUMO}

O presente trabalho tem como objetivo relacionar as recentes manifestações políticas dos setores conservadores da sociedade brasileira com as descrições de Émile Durkheim sobre manifestações religiosas primitivas, tendo como base o livro As formas elementares da vida religiosa, focando-se nos aspectos menos racionais destas manifestações.

Palavras-chave: Émile Durkheim; Sociologia Clássica; Fanatismo; Política; Sociologia da Religião.

\begin{abstract}
This work intends to relate the recent political manifestations of conservative groups of the Brazilian society to Émile Durkheim's descriptions about religious manifestations, based on the book "The Elementary Forms of Religious Life", focusing on the least rational aspects of such manifestations.
\end{abstract}

Keywords: Émile Durkheim; Classical Sociology; Fanaticism, Politics; Sociology of Religion.

${ }^{1}$ Graduanda no Bacharelado em Ciências Sociais da Universidade Federal do Ceará (UFC).E-mail: analuiza.silvaj@gmail.com 


\section{Sobre o livro}

Weste livro, o sociólogo francês Émile Durkheim se comprometeu a encontrar leis que pudessem ser verificadas em qualquer fenômeno religioso, da sociedade mais primitiva à mais recente. Ele utilizou de uma abordagem quase etnográfica, semelhante à da Antropologia clássica, tirando conclusões a partir de etnografias disponíveis à época (fim do século XIX e início do século XX).

Durkheim começou a abordar o fenômeno religioso em 1894, chegando a publicar um artigo em L'Année Sociologique intitulado De la Définition des Phénomènes Religieuses (WEISS, 2012), ainda que de maneira restrita, ainda considerando a religião apenas como "uma instituição social que existia com a função de assegurar o equilíbrio da sociedade, agindo como uma forma de disciplina social” (WEISS, 2012, p. 96). Ao entrar em contato com outros autores que já trabalhavam com a temática da religião, dentre eles o teólogo escocês Robertson Smith, Durkheim alterou sua abordagem e passou a pesquisar mais profundamente o tema (WEISS, 2012).

Entender uma religião numa sociedade moderna é extremamente difícil devido à complexidade de seus rituais. Então o autor opta por buscar entender as religiões recentes em suas formas elementares, com base nas sociedades simples, através de um resgate histórico, que seria olhar para o passado para compreender as categorias fundamentais de algo que existe no presente.

Seu método é consultar as principais etnografias de sua época e tentar tirar delas uma constante para todas as manifestações religiosas. "Como descobrir o fundo comum da vida religiosa sob a luxuriante vegetação que a recobre?” (DURKHEIM, 1978, p. 208). 
Como decisão estratégica, o autor escolheu o totemismo australiano como seu objeto de investigação, e a partir dele desenvolveu relações capazes de nos fazer compreender melhor o que é religião.

O sociólogo estabeleceu como o traço distintivo do pensamento religioso a divisão do mundo em dois domínios, um que compreende tudo o que é sagrado, outro, tudo que é profano (DURKHEIM, 1996). O sagrado e o profano se localizam em dois mundos entre os quais nada existe em comum. Durkheim declara que esse contraste é universal - se encontra em todas as formas de manifestações religiosas conhecidas.

\section{Semelhanças entre as formas elementares da vida religiosa e as manifestações políticas no Brasil}

O característico do fenômeno religioso é que ele supõe sempre uma divisão bipartida do universo conhecido $e$ conhecível entre dois gêneros que compreendem tudo o que existe, mas que se excluem radicalmente.

(DURKHEIM, 1996, p. 24)

Poderíamos assemelhar tal descoberta do autor ao contexto político recente do Brasil, que preza pela divisão partidária quase binária - entre esquerda x direita, “comunistas" ou "liberais" - em que quem integra um grupo não pode integrar o outro. Assim como o sagrado não pode ser tocado pelo profano, e os dois não podem ocupar o mesmo espaço (DURKHEIM, 1996), quem se considera de "esquerda” não pode coexistir com quem se considera de "direita".

Tendo em mente que as noções atuais que definem os termos "esquerda" e "direita" no Brasil se relacionam mais com um posicionamento ideológico do que econômico, e estes mesmos conceitos têm definições diferentes em países diferentes por causa de distintos contextos histórico-políticos (MADEIRA e TAROUCO, 2011), delimito 
aqui a definição que utilizarei neste ensaio: a esquerda brasileira reconhecidamente defende os direitos das minorias sociais (como os negros, a comunidade LGBT) e a diminuição da desigualdade social, e a direita brasileira reconhecidamente preza pela defesa da moral tradicional e pela conservação das hierarquias sociais.

No livro, Durkheim defende que a noção de que a religião teria surgido de um súbito "encantamento" do homem primitivo diante da natureza é recente, advinda das ciências positivas. Os deuses serviriam menos para explicar anomalias do que para explicar o ritmo das marés e a vinda das chuvas (DURKHEIM, 1996). A tarefa essencial das religiões é manter o curso normal da vida. A vida primitiva normal era monótona, prezava-se a regularidade de seus dias e da ação da natureza.

As concepções religiosas têm por objeto, acima de tudo, exprimir e explicar, não o que há de excepcional e anormal nas coisas, mas, ao contrário, o que elas têm de constante e regular (DURKHEIM, 1996, p. 10)

A política, a meu ver, tem uma missão semelhante: manter a normalidade da vida social. Os primeiros contratualistas elegeram a manutenção do bem-estar social como o objetivo primário da existência do Estado. Thomas Hobbes, John Locke e Jean-Jacques Rousseau afirmavam que o bem-estar social seria atingido depois que a população entregasse a um governante a autonomia para governar as suas vidas. Este deveria prover a segurança de seus súditos, definir como serão alocados recursos escassos e resolver problemas de ação coletiva, e, caso não cumprisse isso, aquela população tinha o direito de se rebelar. As decisões tomadas por aqueles eleitos para nos representar influenciam os nossos sistemas financeiro, educacional e de saúde, a curto e a longo prazo. Tudo, teoricamente, para que possamos exercer plenamente os nossos direitos de cidadãos. É evidente que devemos cobrar deles as condições para que o nosso bem-estar social seja efetivo. 
Assim como um devoto de determinada religião tende a se afastar dela quando percebe que suas preces não estão sendo atendidas, ou quando vê situações incoerentes sendo toleradas naquele meio religioso, o cidadão médio brasileiro tenta se manter distante da política, pois a vê como um beco sem saída, como um empreendimento inerentemente corrupto, que apenas tira e não dá de volta aos seus "súditos", para emprestar o termo utilizado pelos contratualistas. A política, aí, perdeu o seu sentido original de manter a normalidade da vida social e resolver as demandas sociais e passou a ser um fardo materializado em impostos abusivos e escândalos de corrupção.

\section{A religião faz parte da experiência social - assim como a política.}

A religião deve ser algo eminentemente coletivo

(DURKHEIM, 1996, p. 32)

Quando leio sobre a religião ser algo eminentemente coletivo, imediatamente me lembro das manifestações dos eleitores de Jair Bolsonaro que se reuniam às centenas em pontos da cidade de Fortaleza notadamente frequentados pela elite local, como a Praia de Iracema e a Praça Portugal, para realizar coreografias ao som de suas principais músicas de campanha (O POVO, 2018). Assim como a religião, a política se manifesta na coletividade, com seus principais "rituais" se caracterizando pela ação de multidões movidas em direção a um objetivo, seja esse objetivo atingir um êxtase religioso ou declarar suas preferências políticas.

A religião é uma forma de cultura e, como tal, consiste em crenças, normas, ideias e valores compartilhados que criam uma identidade comum entre um grupo de pessoas - uma comunidade moral, para utilizar um termo de Durkheim. O autor, de fato, enfatiza as 
relações de afinidade na religião quando diz que "os indivíduos que compõem essa coletividade sentem-se ligados uns aos outros pelo simples fato de terem uma fé comum" (DURKHEIM, 1996, p. 28). A religião faz você se encontrar na sua coletividade, explica o seu mundo e lhe oferece um refúgio. Se você sente o seu mundo ser ameaçado, você vai fazer de tudo para se proteger.

Em cerimoniais coletivos, um sentido de solidariedade grupal é afirmado e intensificado, naquilo que Durkheim chamava de efervescência coletiva - o sentimento fortalecido de energia que é gerado em reuniões e eventos coletivos (GIDDENS, 2012).

Em As regras do método sociológico (DURKHEIM, 2011), Durkheim descreve o que ele chama de correntes sociais. São

\begin{abstract}
as grandes manifestações de entusiasmo, de indignação e de piedade que se desencadeiam nas assembleias e não têm a sua origem em nenhuma consciência particular. Chegam a cada um de nós do exterior e são suscetíveis de nos arrastar contra a nossa vontade. (...) É por isso que, uma vez dispersa a assembleia e acabada a ação das influências sociais sobre nós, logo que ficamos a sós, os sentimentos por que passamos tornam-se estranhos em que já não nos reconhecemos. (...) É por isso que indivíduos perfeitamente inofensivos na sua maioria podem, quando reunidos em multidão, deixar-se arrastar a cometer atrocidades (DURKHEIM, 2011, p. 34).
\end{abstract}

A experiência religiosa é uma expressão da experiência social. Sabendo que os rituais têm a função social de manter a sociedade coesa, e tendo em mente que aqui estamos comparando manifestações religiosas com manifestações políticas, quando os seguidores de determinado grupo político veem desafiados os seus ideais e ridicularizada a sua militância, eles sentem que seu mundo não lhes pertence mais, que sofrem opressão por exercerem seus direitos políticos, e por isso farão de tudo para reaver aquela sensação de segurança que lhes é familiar. E aqui surgem os casos de violência, quase 
sempre realizados por grupos, pois o indivíduo tenta a todo custo manter a estrutura de mundo que ele já conhece, mesmo que seja pelas próprias mãos, e lutará contra tudo e todos que ele imagine que representem algum tipo de ameaça a ela.

\section{Novos deuses, novas devoções}

Durkheim, assim como Karl Marx e Max Weber, acreditava que, com o desenvolvimento das sociedades modernas, a influência da religião tradicional diminui. A expectativa era de que quando os "antigos deuses" estivessem mortos, seriam celebrados valores tipicamente humanistas e políticos, como a liberdade, a igualdade e a cooperação social (GIDDENS, 2012). O que se constatou é que os deuses apenas mudaram de forma, e atualmente a devoção antes destinada aos símbolos nas igrejas é destinada a figuras públicas, normalmente as que falam "o que o povo quer ouvir", ainda mais em tempos de internet generalizada.

Tendo em mente que a religião continua a ser uma parte central da experiência humana, ainda influenciando a maneira como percebemos e reagimos ao ambiente em que vivemos (GIDDENS, 2012), não é de se admirar que a política tenha incorporado elementos antes característicos das manifestações religiosas. Durkheim relaciona a religião à natureza geral das instituições de uma sociedade, instituições essas que, normalmente, são comandadas pelos setores políticos.

É perceptível que, na história recente do nosso País, a política perdeu sua dimensão racional instrumental (HORKHEIMER, 2015) e ganhou, mais do que nunca, uma dimensão de religião, com direito aos "ritos", às "paixões”, aos "estados de efervescência” e à criação dos "mitos", tudo isso incorporado às figuras políticas em evidência a cada época. O lado no qual o indivíduo se identifica politicamente seria o 
"sagrado", e o lado oposto ideologicamente a ele seria o "profano". Qualquer potencial ameaça (e isso fica ao critério do "crente") do profano ao sagrado deve ser reprimida, ou mesmo eliminada.

A religião fundamentalista ainda oferece algum consolo e apoio emocional, mas sua influência diminuiu à medida que a modernidade foi penetrando em quase todas as áreas da vida (GIDDENS, 2012).

Pego emprestada a fala de Durkheim sobre a fundação da sociologia, de que nenhuma instituição humana poderia repousar sobre o erro, sobre a mentira, (DURKHEIM, 1978) e a amplio para a política: todas as manifestações políticas devem ser consideradas, afinal de contas cada uma delas expõe diferentes aspectos da existência humana, expõe como cada grupo social enxerga o mundo. Mas só porque as manifestações são válidas, não significa que tudo que sai delas é verdadeiro; o principal legado da eleição presidencial de 2018 é a certeza de que trabalhar com a verdade e os fatos empíricos não é mais quesito obrigatório nas campanhas políticas - vide as fake news ("notícias falsas") propagadas nas redes sociais pela ala conservadora da disputa (EXAME, 19 de outubro de 2018). É o que Andrew Sullivan, escritor e jornalista britânico, chama de "democracia midiática" (PIAUÍ, 2016).

\section{A divisão do sagrado e o profano na política brasileira}

A dinâmica do sagrado e do profano se confirma tanto na ala da direita quanto na ala da esquerda, já que ambas prezam pelos seus expoentes conservadores e tendem a cercarem-se em suas bolhas, quase como congregações religiosas, que adoram seus iguais e desencorajam quaisquer críticas internas.

Esse isolamento fez com que alguns grupos políticos se fortalecessem diante do cenário político brasileiro enquanto outros, 
isolados entre seus próprios ouvintes, se negavam a debater com seus opositores.

Tendo acesso aos discursos da maioria dos eleitores do candidato conservador, Jair Bolsonaro, é possível perceber que eles se sentem desamparados diante do aumento da insegurança pública, pelo descaso nas áreas da saúde e da educação (GAZETA DO POVO, 17 de setembro de 2018), ainda mais com os recentes escândalos de corrupção nas gestões do principal partido de esquerda do País, o Partido dos Trabalhadores (PT).

E é isto que os eleitores procuram em Bolsonaro: um refúgio para as suas frustrações com o governo e solução para os descasos na vida pública, que, segundo eles, são culpa exclusiva das políticas públicas do PT e do empoderamento das minorias sociais. A pesquisadora Isabela Kalil, que traçou perfis dos eleitores de Bolsonaro, $\operatorname{diz}$

Essas pessoas se sentiram seduzidas pelo discurso do medo propagado por ele e passaram a ver a esquerda como arrogante intelectualmente, um papel que não foi muito produtivo e deixou um campo em aberto pra que esses discursos de ódio e medo circulassem cada vez mais (KALIL, 2018).

\section{A origem da reação dos setores conservadores da sociedade brasileira}

Andrew Sullivan descreve um fenômeno semelhante nos Estados Unidos pré-eleições de 2016, com o terreno dividido entre os setores conservadores que queriam uma "América grandiosa de novo" e os setores de esquerda, principalmente liderados pelas personalidades intelectuais. 
Grande parte da esquerda passou a ver a classe trabalhadora branca não mais como uma aliada, mas basicamente como um grupo de pessoas preconceituosas, misóginas, racistas e homofóbicas, condenando os que estão muitas vezes nos degraus mais baixos da economia a ficar também no degrau mais baixo da cultura.

A classe trabalhadora branca, ao assistir a seus valores morais serem ridicularizados, sua religião ser considerada primitiva e suas perspectivas econômicas dizimadas, agora descobre que até mesmo o sexo e a raça a que pertencem na verdade, a própria forma como falam sobre a realidade são vistos como uma espécie de problema que o país deve tentar superar.

Essa parte da classe trabalhadora, já alienada, ainda tem que ouvir - e como poderia não ouvir? - os sermões, tão fáceis e loquazes, de que "os homens brancos heterossexuais" são a origem fundamental de todos os nossos males.

A metástase do "politicamente correto" de Trump: uma renovada e crescente paixão progressista por igualdade racial e sexual - uma igualdade de resultados, e não a aspiração liberal à mera igualdade de oportunidades (SULLIVAN, 2016).

No Brasil, os setores populares, a “esquerda”, especialmente aqueles incluídos nos meios acadêmicos, adquiriram uma postura que mais desencorajava o debate sobre assuntos de interesse popular do que encorajava. Portanto, os setores conservadores, especialmente as classes mais baixas, ao procurarem na esquerda solução e apoio para seus dilemas, encontraram apenas ofensas e olhos revirados. Quem lhes estendeu a mão foi um político radical, que prega o acesso generalizado às armas de fogo (para que essas pessoas supostamente pudessem proteger a si próprias e suas famílias), o fim dos principais direitos sociais e das liberdades civis, a troco de um Brasil supostamente mais seguro e sem privilégios.

Durkheim define que a estrutura política de uma sociedade é apenas a maneira como os diferentes segmentos que a compõem se habituaram a viver uns com os outros (DURKHEIM, 2011). 
No clássico livro "Fanatismo e movimentos de massa", o filósofo norte-americano Eric Hoffer esboça a dinâmica de um genuíno movimento de massa e dos fatores que levam à sua criação. $\mathrm{O}$ autor tinha em mente as turbulências na Europa da primeira metade do século XX, mas suas descrições foram consideradas tão precisas que o livro se tornou um guia para o estudo sobre as manifestações fanáticas de qualquer época.

Hoffer define o fator principal que distingue os conservadores dos radicais: sua relação com o futuro. "As pessoas com senso de realização acham o mundo bom e gostariam de conservá-lo tal como é, enquanto que os frustrados favorecem a mudança radical.” (HOFFER, 1968, p. 10)

A esperança e o entusiasmo são importantes para determinar o resultado dos movimentos. "O que parece contar mais do que a posse de instrumentos de poder é a fé no futuro. (...) Nenhuma fé tem poder a menos que tenha também fé no futuro." (HOFFER, 1968, p. 12). O que dizer de quem quer a mudança para voltar ao passado?

De acordo com o autor, todos os verdadeiros movimentos de massa originam-se de uma sensação coletiva de frustração aguda. Não desespero, tampouco revolta, nem resignação - mas frustração, num crescendo.

Os movimentos de massa raramente surgem quando a opressão ou a miséria estão no auge (digamos, em 2008 ou 2013); eles tendem a aparecer quando, ao que tudo indica, o pior já passou, mas o futuro não promete ser muito melhor (digamos, 2016). É quando a raiva começa a tomar o lugar da racionalidade.

Após o sofrimento da recessão ou do desemprego, e apesar do esforço e do trabalho duro, com os salários ainda estagnados ou em queda, o futuro se estende à nossa frente como uma espécie de alívio fora do alcance. 
O medo do futuro faz com que nos inclinemos contra ele e nos agarremos ao presente, enquanto que a fé no futuro torna-nos receptivos às mudanças (HOFFER, 1968, p. 13).

Quando aqueles que ajudaram a criar a última recessão não precisam enfrentar suas consequências, mas ganham novas e fabulosas riquezas, a raiva vai aumentando. E canaliza-se essa raiva para os setores mais próximos e que pareçam ser tão ou mais responsáveis por essa crise.

Anthony Giddens afirma que os movimentos sociais estão entre as formas mais poderosas de ação coletiva (GIDDENS, 2012). Campanhas persistentes e bem organizadas podem trazer resultados dramáticos - e constatamos isso no cenário político brasileiro em 2018. A ascensão dos novos movimentos sociais também reflete alguns dos novos riscos que as sociedades humanas enfrentam atualmente. As condições estão prontas para os movimentos sociais, à medida que, cada vez mais, as instituições políticas tradicionais têm dificuldade para lidar com os desafios que surgem (GIDDENS, 2012).

\title{
O entrelaçamento dos movimentos de massa
}

\author{
É raro que um movimento de massa seja totalmente de um \\ determinado caráter. Geralmente apresenta algumas facetas \\ de outros tipos de movimentos, e às vezes de dois ou três \\ movimentos num só. \\ (HOFFER, 1968, p. 21)
}

Todo movimento social oscila entre várias searas, ora se sobressai o seu aspecto político, ora se sobressai o seu aspecto religioso. O último se caracterizaria principalmente na utilização de símbolos (HOFFER, 1968) para identificar o seu ideal, na crença em um futuro 
melhor para seus adeptos e, quase sempre, na aparição de um "eleito" para resolver a situação.

Todo movimento de massa é, num certo sentido, uma migração - um movimento em direção à terra prometida; e quando se torna viável, ocasiona uma verdadeira migração (HOFFER, 1968, p. 24).

Quando Hoffer fala sobre entrelaçamento de movimentos de massa, penso imediatamente nas diversas justificativas dos eleitores de Jair Bolsonaro, cujos discursos sempre convergem para declarações semelhantes - sobre ele "ser o que o Brasil precisa", chamam-no de "nosso capitão", bradam que ele irá cumprir sua promessa de campanha de "acabar com a corrupção". Alguns fazem questão de chamá-lo de Messias, seu segundo nome, com o objetivo de associá-lo à Jesus Cristo, claramente relacionando sua figura com a vinda de um profeta que irá trazer as boas novas para o Brasil (BUZZFEED BRASIL, 20 de outubro de 2018).

Não é à toa que o seu principal "apelido" é Mito - mais consistente com a teoria durkheiminiana impossível, que trata do "verniz" que cobre os ritos. O mito é o que possibilita a longevidade dos costumes, ao cobrir com fantasia e espanto as narrativas orais passadas de geração em geração. O papel de "Mito" que Bolsonaro assumiu tem uma carga de responsabilidade que tem origens mais antigas do que ele pode imaginar, como o próprio Durkheim elabora a seguir.

É verdade que [o naturismo] um ponto de partida no real, nas sensações que os fenômenos da natureza provocam em nós; mas, pela ação prestigiosa da linguagem, essa sensação se transforma em concepções extravagantes. O pensamento religioso só entra em contato com a realidade para cobri-la em seguida com um véu espesso, que dissimula suas formas verdadeiras; esse véu é o tecido de crenças fabulosas que a mitologia produz. (DURKHEIM, 1996, p. 72-73). 
Um mesmo movimento de massa, a princípio político, mescla-se com aspectos religiosos e nacionalistas. Uma mesma congregação pode ter várias nuances - um ritual é tanto religioso quanto é político (DURKHEIM, 1996) - e isso não seria diferente nas manifestações políticas recentes no Brasil.

Tanto no presente como na história, vemos a sociedade incessantemente criar de todas as maneiras coisas sagradas. Se ela vier a se apaixonar por um homem, se acreditar descobrir nele as principais aspirações que a agitam, assim como os meios de satisfazê-las, esse homem será posto numa categoria à parte e como que divinizado. Ele será investido pela opinião de uma majestade inteiramente análoga à que protege os deuses. (...) O sentimento experimentado nessas circunstâncias é tão próximo do sentimento religioso que muitos povos o confundiram (DURKHEIM, 1996, p. 218-219).

Ao longo do presente trabalho, busquei desenvolver a ideia de que os argumentos expostos por Durkheim em As formas elementares da vida religiosa são bastante pertinentes para explicar o Brasil atual, envolto em disputas ideológicas e políticas que mais se inclinam ao irracional do que ao racional, que, idealmente, seria o domínio onde descansa a política. Os eleitores de ambos os lados, conservadores e progressistas, se encontram em estados de efervescência quando reunidos em grandes grupos que defendem seus ideais, seja em manifestações ou mesmo em atos públicos, característica já descrita por Durkheim em suas principais obras, enfatizando o aspecto coletivo das manifestações populares e religiosas.

Émile Durkheim é um autor atemporal, e sua obra, mesmo depois de mais cem anos, continua contribuindo para abrir os olhos dos futuros cientistas sociais. 


\section{REFERÊNCIAS}

CASTRO, Celso. Textos básicos de antropologia: cem anos de tradição. Rio de Janeiro: Zahar, 2016.

BUZZFEED BRASIL. Eleitores - Deus, Antipetismo e Bolsonaro. Youtube. 20 de outubro de 2018. Disponível em: https://www.youtube.com/watch?v=SgDjVEy2vrg Acesso em: 25 de fevereiro de 2019.

DURKHEIM, Émile. As formas elementares da vida religiosa. São Paulo, SP: Abril Cultural, 1978. (Coleção Os Pensadores).

. As formas elementares da vida religiosa: o sistema totêmico na Austrália. São Paulo: Martins Fontes, 1996.

As regras do método sociológico. São Paulo: Martin Claret, 2011.

EXAME ABRIL. Empresários bancam disparos anti-PT no WhatsApp, diz Folha; Haddad reage. Exame Abril, 19 de outubro de 2018. Disponível em: https://exame.abril.com.br/brasil/empresarios-bancamdisparos-anti-pt-no-whatsapp-diz-folha-haddad-reage/ Acesso em: 25 de fevereiro de 2019.

GAZETA DO POVO. "Por que o eleitor de Bolsonaro é tão fiel? Com a palavra, o próprio eleitor". Gazeta do Povo, 17 de setembro de 2018. Disponível em: https://www.gazetadopovo.com.br/eleicoes/2018/porque-o-eleitor-de-bolsonaro-e-tao-fiel-com-a-palavra-o-proprio-eleitor4miyimyqh3soyeko5g71g3cb2 Acesso em: 25 de fevereiro de 2019.

GIDDENS, Anthony. Sociologia. Porto Alegre: Penso, 6 ed., 2012.

HOFFER, Eric; JATOBÁ, Sylvia. Fanatismo e movimento de massa. Rio de Janeiro: Lidador, 1968.

HORKHEIMER, Max. Eclipse da razão. São Paulo: Editora Unesp, 2015.

KALIL, Isabela Oliveira. Quem são e no que acreditam os eleitores de Jair Bolsonaro. [S.l.: s.n.], 2018. xx p. Disponível em: $<$ https://bit.ly/2CXMdpH $>$ Acesso em: 25 de outubro de 2018. 
MADEIRA, Rafael Machado; TAROUCO, Gabriela da Silva. Esquerda e direita no Brasil: uma análise conceitual. Revista Pós Ciências Sociais, v. 8, p. 171-185, 2011.

O POVO. Em Fortaleza, apoiadores de Bolsonaro fazem coreografia para o candidato e vídeo viraliza. O Povo, 2018. Disponível em: $<$ https://www.opovo.com.br/noticias/politica/2018/og/em-fortalezaapoiadores-de-bolsonaro-fazem-coreografia-para-o-candida.html> Acesso em: 27 de novembro de 2018.

SUlLIVAN, Andrew. "Trump e os limites da democracia. Por que os Estados Unidos se tornaram um terreno fértil para a tirania." Revista piauí, junho de 2016. Disponível em: $<$ http://piaui.folha.uol.com.br/materia/trump-e-os-limites-dademocracia/> Acesso em: 29 de novembro de 2018.

WEISS, Raquel. Durkheim e as formas elementares da vida religiosa. Debates do NER. Porto Alegre, ano 13, n. 22, p. 95-119, jul/dez, 2012. Disponível em: https://www.lume.ufrgs.br/handle/10183/103432 . 